(1)

CrossMark

\title{
Easier access to mechanical ventilation worldwide: an urgent need for low income countries, especially in face of the growing COVID-19 crisis
}

\author{
Claude Guérin (10) 1,2 and Patrick Lévy ${ }^{3,4}$ \\ Affiliations: ${ }^{1}$ Intensive Care Unit-Réanimation Groupement Hospitalier Centre Edouard Herriot Hospital and \\ Faculty of Medicine Lyon Est, University of Lyon, Lyon, France. ${ }^{2}$ INSERM 955, Créteil, France. ${ }^{3}$ Univ. Grenoble \\ Alpes, Inserm, HP2 laboratory, Grenoble, France. ${ }^{4}$ Grenoble Alpes University, Thorax and Vessels Dept, \\ Physiology and Respiratory Section, Grenoble, France.
}

Correspondence: Patrick Lévy, Physiology and Respiratory Department, EFCR, Hôpital Michallon, CHU Grenoble Alpes, 38043 Grenoble Cedex 9, France. E-mail: Patrick.levyduniv-grenoble-alpes.fr

@ERSpublications

Combining easy-to-build noninvasive ventilator and open-source hardware description, may allow for adequate availability of ventilators to patients in low- and middle-income countries. This is urgently needed in the growing COVID-19 epidemic. https://bit.ly/3f8ZkUR

Cite this article as: Guérin C, Lévy P. Easier access to mechanical ventilation worldwide: an urgent need for low income countries, especially in face of the growing COVID-19 crisis. Eur Respir J 2020; 55: 2001271 [https://doi.org/10.1183/13993003.01271-2020].

That positive pressure mechanical ventilation can save lives was proved during the poliomyelitis epidemics of the 1950s. Since that time there has been a growing increase in the use of ventilatory support, and it has been closely associated with the development of critical care medicine [1]. Positive pressure ventilation can be life-saving in patients with acute severe hypoxaemia that is refractory to more conservative measures. In patients with severe cardiopulmonary distress for whom the effort of breathing is intolerable, mechanical ventilation substitutes for the action of the respiratory muscles [1]. Mechanical ventilation is often lifesaving but is associated with serious complications, in part because it is delivered to patients at high risk of lung or cardiac compromise. These complications may be related to the direct mechanical effects of the intrathoracic pressures generated by the ventilator, to alveolar and systemic inflammation, or to neural stimulation [2]. Endotracheal intubation is a critical procedure [3] in which patients are at risk of respiratory and circulatory compromise. Noninvasive ventilation (NIV) using facial or nasal masks, which has been revealed to be particularly helpful in the long-term treatment of patients with chronic respiratory failure, including in the context of obesity [4], can also improve pulmonary gas exchange rapidly in patients with acute ventilatory failure. As compared with conventional treatment, NIV may reduce the need for endotracheal intubation and thus decrease mortality [1]. Whilst NIV demonstrated a strong evidence for its benefits in patients with acute exacerbations of COPD [5] and cardiogenic pulmonary oedema, it may also be used in the management of patients with acute respiratory distress syndrome (ARDS) [6]. In a sub-study of a large observational study to understand the global impact of severe acute respiratory failure, NIV was used in about $15 \%$ of patients with ARDS, irrespective of the severity of hypoxaemia. However, use of NIV, in comparison with invasive ventilation, had important implications for patient management. Although mortality rate was low in patients successfully managed with NIV,

Received: 19 April 2020 | Accepted after revision: 26 April 2020

Copyright OERS 2020. This version is distributed under the terms of the Creative Commons Attribution NonCommercial Licence 4.0. 
patients who failed NIV had a high mortality. NIV may be associated with a worse intensive care unit outcome than invasive mechanical ventilation in moderate to severe ARDS [6]. Lastly, NIV may be used prior to the occurrence of ARDS or when weaning from invasive mechanical ventilation.

According to its broad use from home to intensive care unit (ICU), including pre-hospital, pneumology ward, emergency and operating room, mechanical ventilation should comply with a large number of specifications. On one side of the spectrum, home mechanical ventilation is noninvasively delivered by using specific bilevel, turbine-driven devices. The ventilators are small, easy to transport, silent, space-saving and their main objectives/challenges are management of leaks, optimal patient comfort and maximal patient-ventilator synchrony for allowing long-term acceptance of mechanical ventilation [7]. These have very sensitive triggers and smart algorithms for cycling the breathing cycle. On the other side, ICU patients receive invasive mechanical ventilation from very sophisticated and costly machines with electromagnetic valves to cycle the breath, a large screen displaying flow, pressure and volume, many ventilatory modes and monitoring of trans-pulmonary pressure, end-expiratory lung volume, or electrical impedance tomography lung imaging, as the most recent implementations from the applied respiratory physiology field. The main goals of ICU ventilators are accuracy, reliability and high performance. Bench studies showed that both home-dedicated and ICU ventilators have variability between brands for, as an example, leak compensation in the former [8] and tidal volume and positive end-expiratory pressure delivery accuracy for the latter [9]. There is, however, overlap as patients with chronic respiratory failure may receive invasive mechanical ventilation at home through a tracheostomy, and ICU patients in acute respiratory failure may be given NIV through dedicated devices. These latter devices compared favourably to ICU ventilators with NIV mode [10]. Some intermediate ventilators used at home can support the life in step-down units, with limitations regarding power and inspiratory oxygen fraction [11]. It is worth mentioning that peripheral devices like interfaces, humidifiers and ventilator circuits are also key items for an efficient mechanical ventilation in any setting.

In the present issue of the European Respiratory Journal, GARMENDIA et al. [12] report on the design and testing of an affordable and easy-to-build noninvasive bilevel pressure ventilator to allow the serious shortage of ventilators to be reduced. This is mainly dedicated to low- and middle-income countries (LMICs). Their ventilator is built using off-the-shelf materials easily available and has a simple design: a high-pressure blower, two pressure transducers and a controller with a digital display, the total retail cost being less than USD 75, and open source construction details provided for replication. The ventilator was evaluated and compared with a commercially available device at the bench using an actively breathing patient simulator and in 12 healthy volunteers submitted to high airway resistance or to simulated restrictive syndrome. The ventilator provided inspiratory/expiratory pressures up to 20/10 $\mathrm{cmH}_{2} \mathrm{O}$, respectively, with a satisfactory functioning when compared to the commercial device. The authors thus concluded that this very low cost bilevel pressure support ventilator was easy-to-build and provided potential use in under-resourced areas of developing countries or during pandemic conditions, such as those imposed currently by severe acute respiratory syndrome coronavirus 2 (SARS-CoV-2) [13].

The ongoing coronavirus disease 2019 (COVID-19) pandemic has stressed healthcare systems all over the world probably as never before. Because COVID-19 results in an acute hypoxaemic respiratory failure that may culminate in ARDS, the number of ICU beds and ventilators have become resources of the utmost value. As the number of ICU beds have been increased dramatically by upgrading step-down units and post-operative recovery rooms, we have been faced with a shortage of ventilators [14-16], probably for the first time since ICU was born, giving rise to ethical issues [17]. The response to the ventilator shortage was multiple: enhancement of the production of existing devices, which requires cooperation between industries with different skills [18], sharing ventilators between two or more patients and the building-up of custom-made and cheap ventilators. This strategy of building reliable and cheap ventilators, even for ICU patients is not new [19], and is reminiscent of when tracheostomy, iron lung and early ICU ventilators were used in an emergency at the time of the poliomyelitis epidemic in 1952 [20]. It could be that this response resulted in a substandard delivery of mechanical ventilation. However, as in our daily life, the COVID-19 pandemic forces us to catch the essential elements of technological support. As an example, even though ICU ventilators are equipped with many ventilatory modes, only two of them, volume control and pressure support, are actually used in more than $80 \%$ of ICU patients [21]. Hypoxaemic acute respiratory failure due to SARS-CoV-2 does not check every item of the Berlin definition for ARDS [22] and is characterised by a marked hypoxaemia with relatively preserved lung compliance [23]. Therefore, whilst some authors advocate to deliver oxygen and delay intubation [24], some others preferred rapid intubation [25]. NIV is not an option in this setting for different reasons. In Middle East respiratory syndrome-related coronavirus infection it was associated with a high rate of failure [26]. In a large database of ARDS patients, NIV was associated with higher mortality [27], presumably because it delays intubation. Furthermore, it can enhance virus spread, and risk of ventilator-induced lung 
injury due to large tidal volume [28]. Clinicians are indeed reluctant to use NIV in the current COVID-19 pandemics [29]. A recent clinical update indicated that in case of COVID-19 ARDS, noninvasive support may stabilise the clinical course in mild cases, provided that the patient does not exert excessive inspiratory efforts. However, if respiratory drive is not reduced by oxygen administration and/or noninvasive support, persistently strong spontaneous inspiratory efforts simultaneously increase tissue stresses and raise pulmonary trans-vascular pressures, vascular flows and fluid leakage. Deterioration of lung function may then rapidly ensue [30].

During the current COVID-19 epidemics, the institution of interventions such as sanitary cordon, traffic restriction, social distancing, home quarantine, centralised quarantine, and symptom survey was temporally associated with reduced effective reproduction number of SARS-CoV-2 (secondary transmission) and the number of confirmed cases [31]. The implementation of these measures helped to control the first wave of the COVID-19 pandemic in China. The ultimate goal is to remain below the ICU capacity. In France for instance, this ICU capacity underwent a large increase in the past weeks to face the rapid surge of patients in critical condition. Capacities have been stretched in the most affected regions, and patients have been transferred to other regions for adequate care. Focusing on the longer term, systematic investments to further increase such capacity (including structures, material, personnel, training programmes) may help in accelerating the gain of immunity in the population and reducing the overall duration of the epidemic [32]. Indeed, the situation could become dramatic in LMICs if the COVID-19 pandemic spreads. In an international audit of ICU patients worldwide assessing variations between hospitals and countries in terms of ICU mortality, a significant association was found between the risk of death and global national income, suggesting also that ICU organisation has an important effect on risk of death [33]. However, strategies to prevent and manage critical illness must be extrapolated to regions where diagnostic, monitoring and therapeutic technologies widely available in high-income countries are lacking [34]. Mechanical ventilators designed to meet the challenges of resource-limited settings, such as that reported by Garmendia et al. [12], are now more widely available. However, until now, their dissemination has been slow, partly due to a lack of trained clinicians and institutional reticence. Challenges to the safe delivery of mechanical ventilation in these settings also include maintaining a reliable supply of important disposables (filters, circuits), training and retaining biomedical engineers for ventilator maintenance, and ensuring patient safety when arterial blood gas analysers are not available [34]. A relevant comment in the paper by GARMENDIA et al. [12] was that the medical device industry that searches and delivers life-enhancing innovative solutions, is a model which is hardly suitable to low-income settings that are usually resource scarce, and where the provision of even adequate basic services to the population is challenging. They thus suggested that their approach combining an easy-to-build noninvasive ventilator and open-source hardware description, may not only allow for adequate availability of ventilators to patients but may also contribute to the development of the local industry network in LMICs. The growing COVID-19 crisis threatens to disproportionately hit developing countries, not only as a health crisis in the short term but as a devastating social and economic crisis over the months and years to come [35]. Under-resourced hospitals and fragile health systems are likely to be overwhelmed. This may be further exacerbated by a spike in cases, as up to 75 per cent of people in the least developed countries lack access to soap and water. Thus, any attempt to tackle the coming health issues in LMICs is just very welcome.

Conflict of interest: C. Guérin has nothing to disclose. P. Lévy has nothing to disclose.

\section{References}

Tobin MJ. Mechanical ventilation. N Engl J Med 1994; 330: 1056-1061.

Pham T, Brochard LJ, Slutsky AS. Mechanical ventilation: state of the art. Mayo Clin Proc 2017; 92: 1382-1400. Jaber S, Jung B, Corne P, et al. An intervention to decrease complications related to endotracheal intubation in the intensive care unit: a prospective, multiple-center study. Intensive Care Med 2010; 36: 248-255.

4 Pepin JL, Timsit JF, Tamisier R, et al. Prevention and care of respiratory failure in obese patients. Lancet Respir Med 2016; 4: 407-418.

5 Lightowler JV, Wedzicha JA, Elliott MW, et al. Non-invasive positive pressure ventilation to treat respiratory failure resulting from exacerbations of chronic obstructive pulmonary disease: Cochrane systematic review and meta-analysis. BMJ 2003; 326: 185.

6 Bellani G, Laffey JG, Pham T, et al. Noninvasive ventilation of patients with acute respiratory distress syndrome. insights from the LUNG SAFE Study. Am J Respir Crit Care Med 2017; 195: 67-77.

7 Rabec C, Rodenstein D, Leger P, et al. Ventilator modes and settings during non-invasive ventilation: effects on respiratory events and implications for their identification. Thorax 2011; 66: 170-178.

8 Contal O, Vignaux L, Combescure C, et al. Monitoring of noninvasive ventilation by built-in software of home bilevel ventilators: a bench study. Chest 2012; 141: 469-476.

9 Garnier M, Quesnel C, Fulgencio JP, et al. Multifaceted bench comparative evaluation of latest intensive care unit ventilators. Br J Anaesth 2015; 115: 89-98. 
10 Carteaux G, Lyazidi A, Cordoba-Izquierdo A, et al. Patient-ventilator asynchrony during noninvasive ventilation: a bench and clinical study. Chest 2012; 142: 367-376.

11 Baboi L, Subtil F, Guerin C. A bench evaluation of fraction of oxygen in air delivery and tidal volume accuracy in home care ventilators available for hospital use. J Thorac Dis 2016; 8: 3639-3647.

12 Garmendia O, Rodríguez-Lazaro MA, Otero J, et al. Low-cost, easy-to-build noninvasive pressure support ventilator for under-resourced regions: open source hardware description, performance and feasibility testing. Eur Respir J 2020; 55: 2000846.

13 Grasselli G, Zangrillo A, Zanella A, et al. Baseline characteristics and outcomes of 1591 patients infected with SARS-CoV-2 admitted to ICUs of the Lombardy region, Italy. JAMA 2020; 323: 1574-1581.

14 Ranney ML, Griffeth V, Jha AK. Critical supply shortages-the need for ventilators and personal protective equipment during the Covid-19 pandemic. N Engl J Med 2020; 382: e41.

15 Koonin LM, Pillai S, Kahn EB, et al. Strategies to inform allocation of stockpiled ventilators to healthcare facilities during a pandemic. Health Secur 2020; 18: 69-74.

16 Truog RD, Mitchell C, Daley GQ. The toughest triage-allocating ventilators in a pandemic. N Engl J Med 2020, 382: 1973-1975

17 Armour S. Plan to ration treatment is unfair to frailest patients, advocates say. Wall Street Journal 2020 ; A003. https://www.wsj.com/articles/rationing-plans-in-coronavirus-crisis-draw-growing-discrimination-complaints11586430000 .

18 Thomson Reuters. Coronavirus/France: Un consortium Air Liquide-PSA-Valeo-Schneider pour produire des respirateurs [Coronavirus/France: An Air Liquide-PSA-Valeo-Schneider consortium to produce respirators]. https://www.boursorama.com/bourse/actualites/coronavirus-france-un-consortium-air-liquide-psa-valeo-schneiderpour-produire-des-respirateurs-0ddb10c93c9a76b2dffe2a28d6597130 Date last updated: March 31, 2020.

19 Blanc Q, Sab JM, Philit F, et al. Inspiratory pressure-volume curves obtained using automated low constant flow inflation and automated occlusion methods in ARDS patients with a new device. Intensive Care Med 2002; 28: 990-994.

20 Lassen HC. A preliminary report on the 1952 epidemic of poliomyelitis in Copenhagen with special reference to the treatment of acute respiratory insufficiency. Lancet 1953; 1: 37-41.

21 Esteban A, Frutos-Vivar F, Muriel A, et al. Evolution of mortality over time in patients receiving mechanical ventilation. Am J Respir Crit Care Med 2013; 188: 220-230.

22 Ranieri VM, Rubenfeld GD, Thompson BT, et al. Acute respiratory distress syndrome. the Berlin definition. JAMA 2012; 307: E1-E8.

23 Gattinoni L, Coppola S, Cressoni M, et al. Covid-19 does not lead to a "typical" acute respiratory distress syndrome. Am J Respir Crit Care Med 2020; 201: 1299-1300.

24 Tobin MJ. Basing respiratory management of coronavirus on physiological principles. Am J Respir Crit Care Med 2020; in press [https://doi.org/10.1164/rccm.202004-1076ED].

25 Grasselli G, Pesenti A, Cecconi M. Critical care utilization for the COVID-19 outbreak in Lombardy, Italy: early experience and forecast during an emergency response. JAMA 2020; in press [https://doi.org/10.1001/jama.2020. 4031].

26 Arabi YM, Arifi AA, Balkhy $\mathrm{HH}$, et al. Clinical course and outcomes of critically ill patients with Middle East respiratory syndrome coronavirus infection. Ann Intern Med 2014; 160: 389-397.

27 Bellani G, Laffey JG, Pham T, et al. Noninvasive ventilation of patients with acute respiratory distress syndrome. insights from the LUNG SAFE Study. Am J Respir Crit Care Med 2017; 195: 67-77.

28 Brochard L, Slutsky A, Pesenti A. Mechanical ventilation to minimize progression of lung injury in acute respiratory failure. Am J Respir Crit Care Med 2017; 195: 438-442.

29 Bhatraju PK, Ghassemieh BJ, Nichols M, et al. Covid-19 in critically ill patients in the Seattle region-case series. N Engl J Med 2020; 382: 2012-2022.

30 Marini JJ, Gattinoni L. Management of COVID-19 respiratory distress. JAMA 2020; in press [https://doi.org/10. 1001/jama.2020.6825]

31 Pan A, Liu L, Wang C, et al. Association of public health interventions with the epidemiology of the COVID-19 outbreak in Wuhan, China. JAMA 2020; in press [https://doi.org/10.1001/jama.2020.6130]

32 Di Domenico L, Pullano G, Sabbatini C, et al. Expected impact of lockdown in Île-de-France and possible exit strategies. Available from: https://www.epicx-lab.com/uploads/9/6/9/4/9694133/inserm-covid-19_report_lockdown_ idf-20200412.pdf

33 Vincent JL, Marshall JC, Namendys-Silva SA, et al. Assessment of the worldwide burden of critical illness: the intensive care over nations (ICON) audit. Lancet Respir Med 2014; 2: 380-386.

34 Murthy S, Adhikari NK. Global health care of the critically ill in low-resource settings. Ann Am Thorac Soc 2013; 10: 509-513.

35 United Nations Development Programme. COVID-19: Looming crisis in developing countries threatens to devastate economies and ramp up inequality. United Nations Development Programme News. https://www.undp.org/content/ undp/en/home/news-centre/news/2020/COVID19_Crisis_in_developing_countries_threatens_devastate_economies.html Date last updated: March 30, 2020. 